\title{
Diagnostic Model of Fuel Installation of Marine Diesel Engine
}

\section{Andrzej Grządziela, Agata Załęska-Fornal, Marcin Kluczyk}

The paper presents the results of simulation of marine diesel engine fuel injector malfunction and its effects on engine vibration. The work includes the analysis of the engine internal forces and their mathematical models. Simplifications are proposed to allow analyzing the system in one degree of freedom. The results of vibration simulations for the model with efficient fuel system and improperly adjusted injector are also presented. The comparison of simulation results with vibration measurements on the engine was also performed, the diagnostic model was identified and simulation errors were calculated. The complexity of other internal and external interactions is the subject of other studies by the authors. The paper analyzes only the effects of energy dissipation - vibration as a symptom of changes in the technical condition.

\section{KEY WORDS}

$\sim$ Simulation

$\sim$ Diagnostic model

$\sim$ Fuel installation

$\sim$ Diesel engine

\section{INTRODUCTION}

At present, the diagnostics of the marine propulsion engines and generators is a standard procedure on-line, offered by all engine manufacturers. The diagnostic systems are part of a wider management and monitoring platform called IPMS. Such arrangements have become widely available since the $21 \mathrm{st}$ century. Due to the lifetime of the ship of up to 50 years and its equipment, it is reasonable to consider the diagnostic tools for marine diesel engines manufactured before the implementation of the modern monitoring systems. Lots of existing marine engines do not have a microprocessor diagnostic system, while the low power engines do not have even the indication valves. Due to the common problem concerning the fuel quality in naval craft, the necessity of assessment of proper operation of the engine fuel system and, above all, the injectors' condition becomes apparent. With regard to the low power engines the vibration diagnostics seems to be one of the more useful and effective methods. Now, the literature is focused mainly on the modelling and diagnostics of fuel installations of the common rail type (Armstrong, 1996; Kiijarvi, 2003; Lalić et al., 2017). In those works, the development of diagnostics of the fuel installations with accustomed injectors and united injectors which are still widely used on ships is presented. The work presents modelling of the dynamic processes on Sulzer 8AL 25/30 engine with properly working fuel injectors and with reduced pressure injection on one cylinder. The object of the study is presented in Figure 1. The obtained results are related to the rotational speed of the engine $n=750 \mathrm{rpm}$ with the moment loads from $\mathrm{T}=20 \%$ $\mathrm{T}_{\max }$ up to $\mathrm{T}=75 \% \mathrm{~T}_{\max }$. 


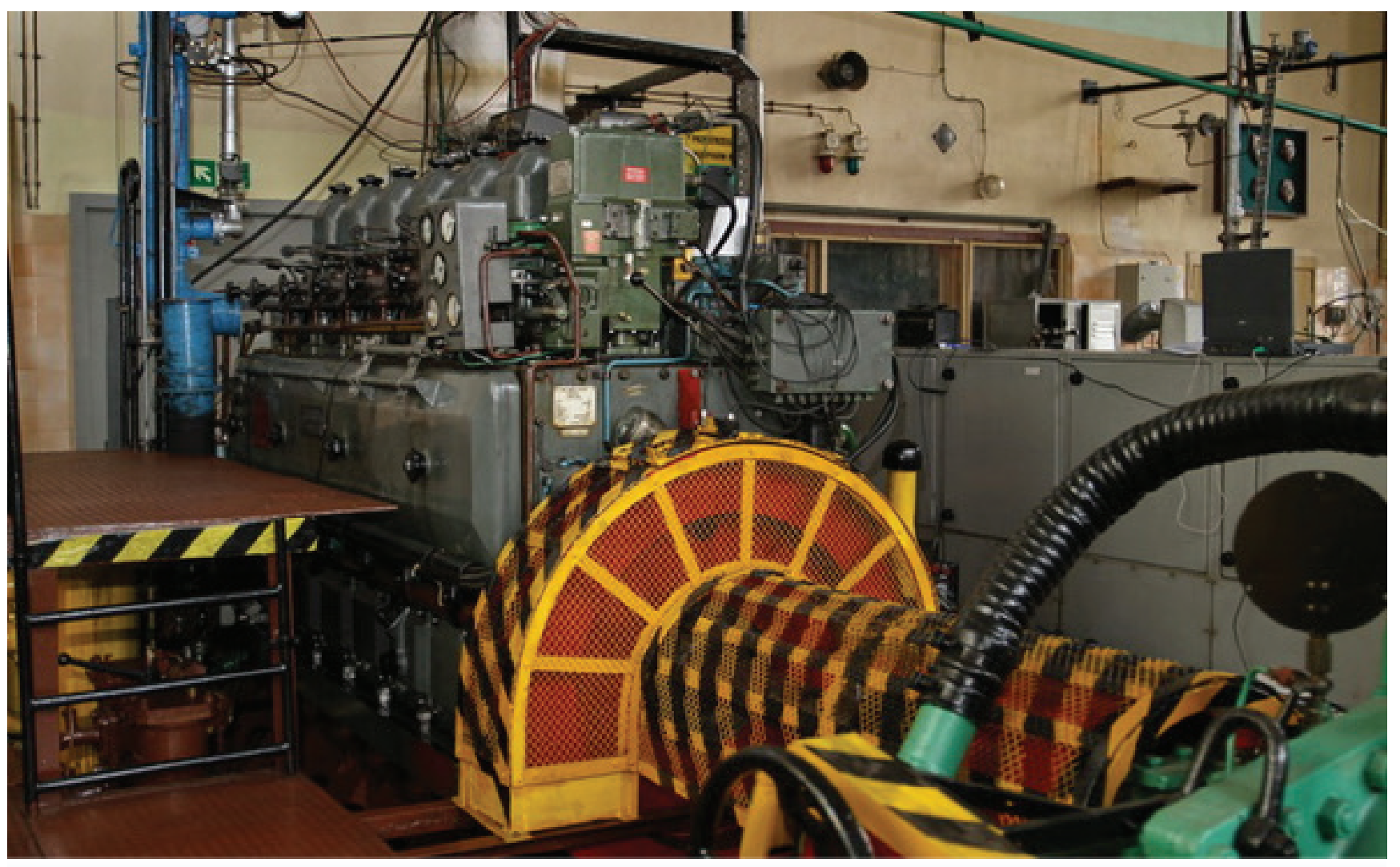

Figure 1.

Sulzer 8AL 25/30 type engine test stand in the Laboratory of the Faculty of Mechanical \& Electrical Engineering of the Polish Naval Academy.

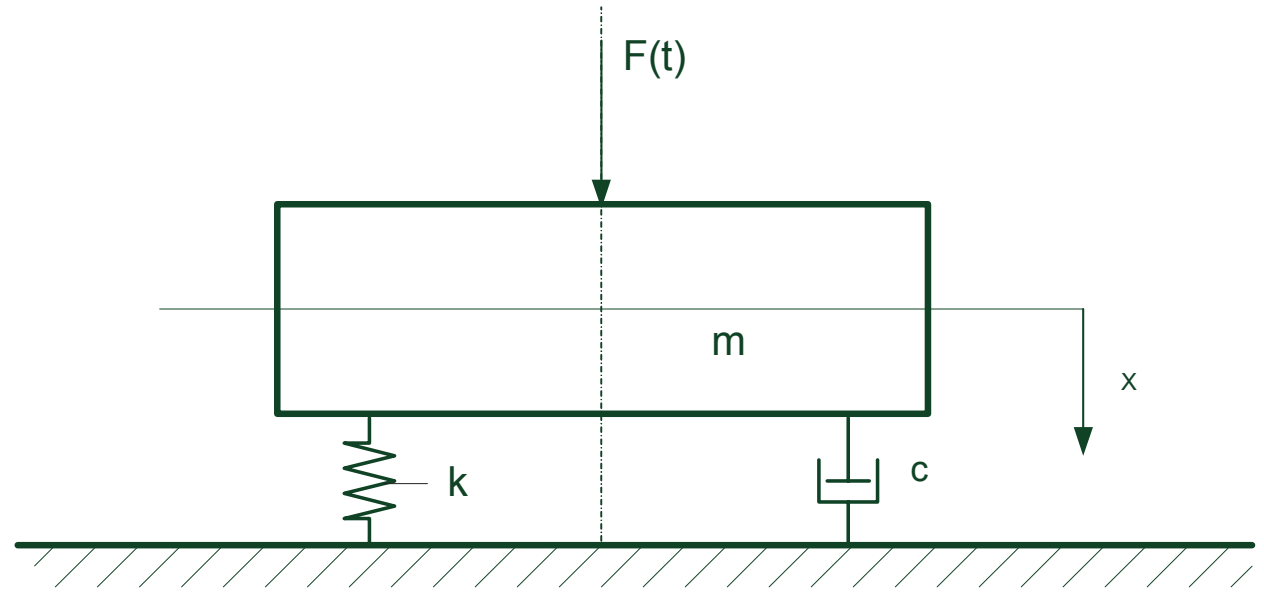

Figure 2.

Simplified model of internal forces excitation on marine diesel engine, where $\mathrm{m}$ - mass of engine, $\mathrm{c}-$ coefficient of damping, $\mathrm{k}$ - coefficient of stiffness. 


\section{MODEL OF INTERNAL FORCES EXCITATION}

Preliminarily, the simplified system with constant force $F$ with the force frequency $\omega$ was analyzed - Figure 2. The following notations are assumed:

- $\quad$ single degree of freedom system with viscous damping,

- additivity internal forces,

- no effect of temperature on stiffness and damping,

- the impact of concentrated forces in the center of gravity,

- equivalent stiffness and damping pads,

- $\quad$ identity of vibration measured in join, and modeled in links. We assume that the external force is cosinusoidal and it is defined by the equation:

$F(t)=F_{0} \cos \omega t$

The general equation of the engine damped vibration motion is of the form:

$m \frac{d^{2} x}{d t^{2}}+c \frac{d x}{d t}+k x=F_{0} \cos \omega t$

The solution of the general equation of vibration motion is the sum the general solution of the homogeneous equation and the particular solution of the inhomogeneous equation. The first part of the solution is an equation with extinguished amplitude, which after some period of time does not have any impact on the solution of the general equation. There is an additive model admitted, relying on summing the particular solutions which are nothing else but the impacts of the internal forces and moments existing in the object studied.

Dividing the equation (2) by $m$ and denoting:

$$
\frac{c}{m}=2 \beta ; \frac{k}{m}=\omega_{0}^{2} ; \quad \frac{F_{0}}{m}=f_{0}
$$

The following is obtained:

$$
\frac{d^{2} x}{d t^{2}}+2 \beta \frac{d x}{d t}+\omega^{2}{ }_{0} x=f_{0} \cos \omega t
$$

The equation (4) is inhomogeneous second order differential equation with constant coefficients. The general solution of that equation $x(t)$ is the sum of a particular solution $x_{s}(t)$ and the general solution of the complementary equation $x_{0}$ $(t)$, i.e.: $x(t)=x_{0}(t)+x_{s}(t)$

$x_{0}(t)=A \cdot e^{-\beta t} \cos (\omega t+\gamma)$

where: $\omega=\sqrt{ }\left(\omega^{2}{ }_{0}-\beta^{2}, \omega_{0}-\right.$ natural frequency of the system.

Finding the particular solution of the inhomogeneous equation $-x_{s}(t)$ is the next step. To the right side of (4) there is temporarily added: $i \cdot f_{0} \sin (\omega t)$, and there the exponential form of the complex number $e^{i \omega}=\cos \omega+i \cdot \sin \omega$ is applied. After the operation, the following form of the equation

$\frac{d^{2} x}{d t^{2}}+2 \beta \frac{d x}{d t}+\omega^{2}{ }_{0} x=f_{0} e^{i \omega t}$

is obtained.

The particular solution is as follows:

$x_{s}=a \cdot f_{0} e^{i \omega t}$

Therefore, the differentials of (8) have the form:

$\frac{d x_{s}}{d t}=i \omega a e^{i \omega t}$

$\frac{d^{2} x_{s}}{d t^{2}}=-\omega^{2} a e^{i \omega t}$

After substituting (9) and (10) into (7), we get:

$-\omega^{2} a+2 i \beta \omega a+a \omega_{0}^{2}=f_{0}$

We obtain the solution when we find the complex amplitude after determining it from:

$a=\frac{f_{0}}{\left(\omega_{0}^{2}-\omega^{2}\right)-2 i \beta \omega}$

The numerator of (12) can be rewritten as:

$\left(\omega_{0}^{2}-\omega^{2}\right)+2 i \beta \omega=\theta \cdot e^{i \varphi}$ 
where:

$\theta=\sqrt{\left.\left(\omega_{0}^{2}-\omega^{2}\right)^{2}+4 \beta^{2} \omega^{2}\right)} ; \varphi=\operatorname{arctg}\left(\frac{2 \beta \omega}{\left(\omega_{0}^{2}-\omega^{2}\right)}\right)$

Therefore the amplitude is:

$a=\frac{f_{0}}{\theta} e^{-i \varphi}$

Taking under consideration the real part of the complex number we get the particular solution:

$$
\begin{aligned}
x_{s}=\operatorname{Re}\left[\frac{f_{0}}{\theta} e^{-i \varphi} e^{i \omega t}\right] & =\operatorname{Re}\left[\frac{f_{0}}{\theta} e^{i(\omega t-\varphi)}\right] \\
& =\frac{f_{0}}{\theta} \cos (\omega t-\varphi)
\end{aligned}
$$

The following equation is the general solution of (7):

$x(t)=-A \cdot \beta e^{-\beta t} \cos (\omega t+\gamma) \frac{f}{\theta} \cos (\omega t-\varphi)$

while its derivatives are as follows:

$$
\begin{aligned}
\dot{x}(t)= & A \cdot e^{-\beta t} \cos (\omega t+\gamma)-A \cdot e^{-\beta t} \omega \cdot \sin (\omega t+\gamma) \\
& -\omega \frac{f_{0}}{\theta} \sin (\omega t-\varphi)
\end{aligned}
$$

$$
\begin{aligned}
\ddot{x}(t)= & A \beta^{2} e^{-\beta t} \cos (\omega t+\gamma)+A \cdot \beta e^{-\beta t} \sin (\omega t+\gamma) \\
& +A \cdot \beta e^{-\beta t} \omega \cdot \sin (\omega t+\gamma)-A \cdot e^{-\beta t} \omega^{2} \cos (\omega t+\gamma)
\end{aligned}
$$

\section{INERTIA AND GAS FORCES SIMULATION}

Inertial forces are produced by non-zero translational and angular acceleration. For the identified mass centers for each element of the piston-crank mechanism, the equations of motion will take the form:

$\sum F_{e x t}+\sum M_{e x t}-m \ddot{r}-l \ddot{q}=0$

where: $F_{\text {ext }} M_{\text {ext }}$ - the external forces and moments,

$I$ - moment of inertia,

$r$ - the position vector of the mass center of link, $m$ - mass,

The first task is to find the unknown constraint forces in a moving mechanism that is reduced to a problem of static equilibrium - D'Alembert principle. The diesel engine pistonconrod-crank mechanism scheme is presented in the Figure 3.

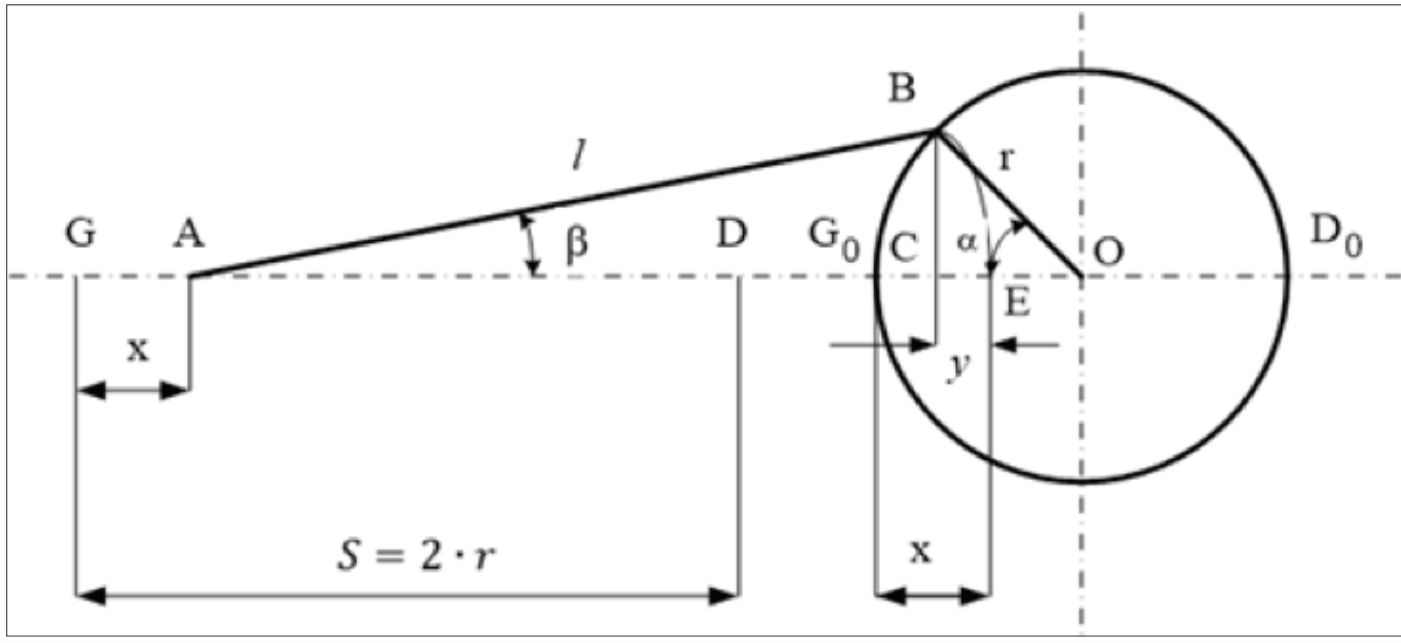

Figure 3.

Diesel engine piston-conrod-crank mechanism schema for inertia forces calculation (Batrak, 2017). 
Small 4-stroke diesel engine is a complex mechanism so that the changes in the moment of inertia as crankshaft rotation function may also be shown as (Batrak, 2017):

$$
\begin{aligned}
& I(a)=I_{C}+m_{C} h^{2} r^{2}+I_{R} \lambda^{2} \frac{\cos a}{\cos \left(180^{\circ}-\beta\right)}+m_{P} r^{2} \\
& \left(\cos a \cdot \operatorname{tg}\left(180^{\circ}-\beta\right)-\sin a\right)^{2}+m_{R} r^{2}\left[(1-j)^{2} \cos ^{2} a\right. \\
& \left.+\left(j \cdot \cos a \cdot \operatorname{tg}\left(180^{\circ}-\beta\right)-\sin a\right)^{2}\right]
\end{aligned}
$$

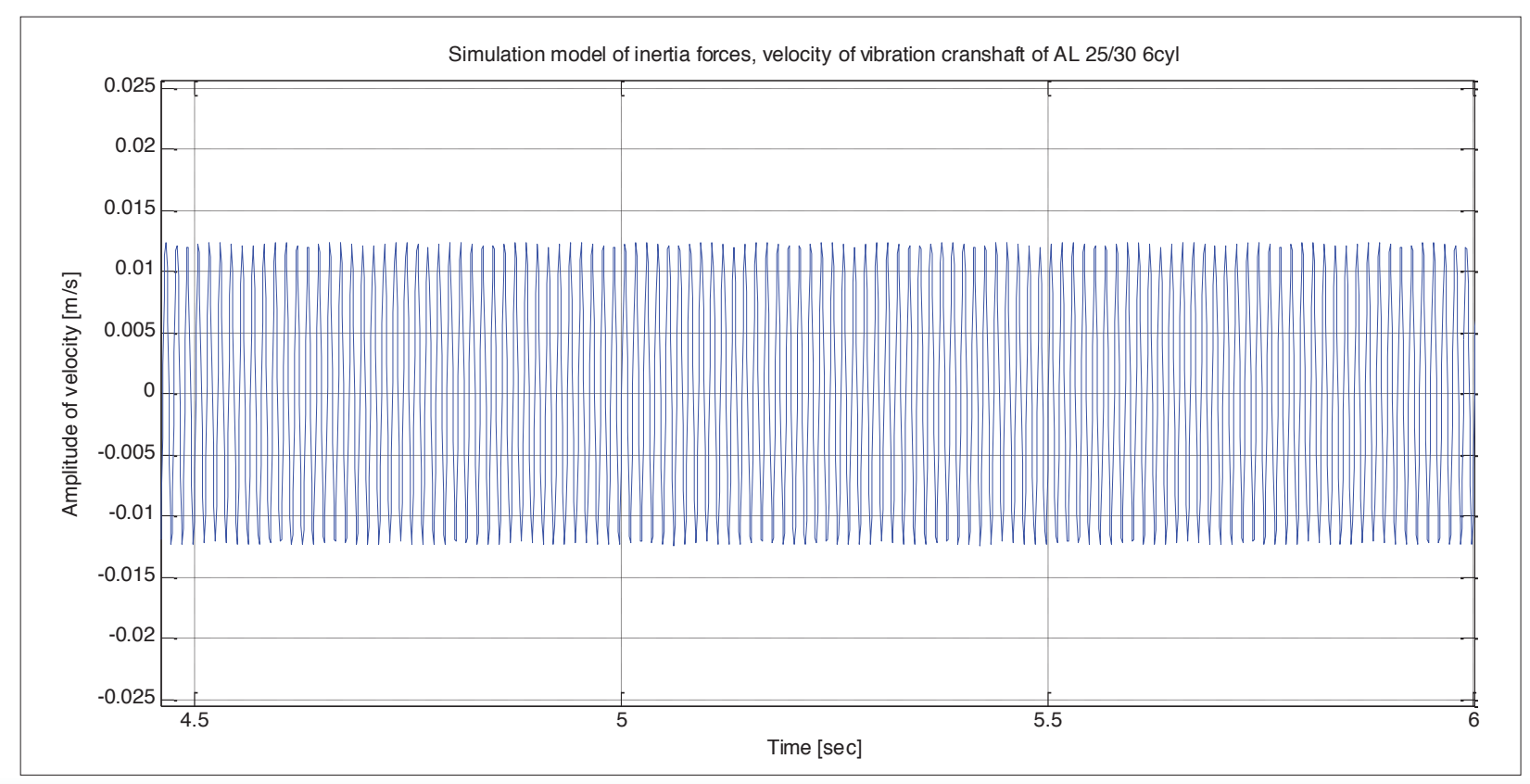

Figure 4.

Result of inertia forces simulation of the crankshaft mechanism of AL 25/30 engine type.

However, these results are often dismissed as unimportant in engines' dynamic calculation, but the authors believe that for the proper model all high energetic forces have to be analyzed.

The next simulations are gas forces excitations of efficient working fuel installation and malfunction of one fuel injector (Jianmin et al., 2011). Figure 5 presents the models of individual, fully efficient injection of fuel installation at the pressure of 17 MPa (blue line), and the simulation of failure of injector at the pressure of $14 \mathrm{MPa}$ (red line) in the domain of crankshaft angle.

The most energetic internal forces are gas pressure pulsation in the cylinders coming from the working process (Carlucci et al., 2006; Sabau, 2012; Yipeng et al., 2014). The important simplification is the assumption of harmonic excitation of gas forces as a time function. Such a simplification is not physically precise because of the relation of gas forces to the rotational speed of the crankshaft, which is not constant in the time domain where:

$\lambda=\frac{r}{l}, h=\frac{O C}{r}, i=\frac{A C}{l}$

Knowledge of the course of the first and second-order acceleration in the crank-piston system makes it possible to present changes in the inertia forces as a function of the crankshaft rotation angle, and thus also the changes in the acceleration of the piston and the connecting rod, as a consequence of the inertia and torque of the crankshaft system - Figure 4. 


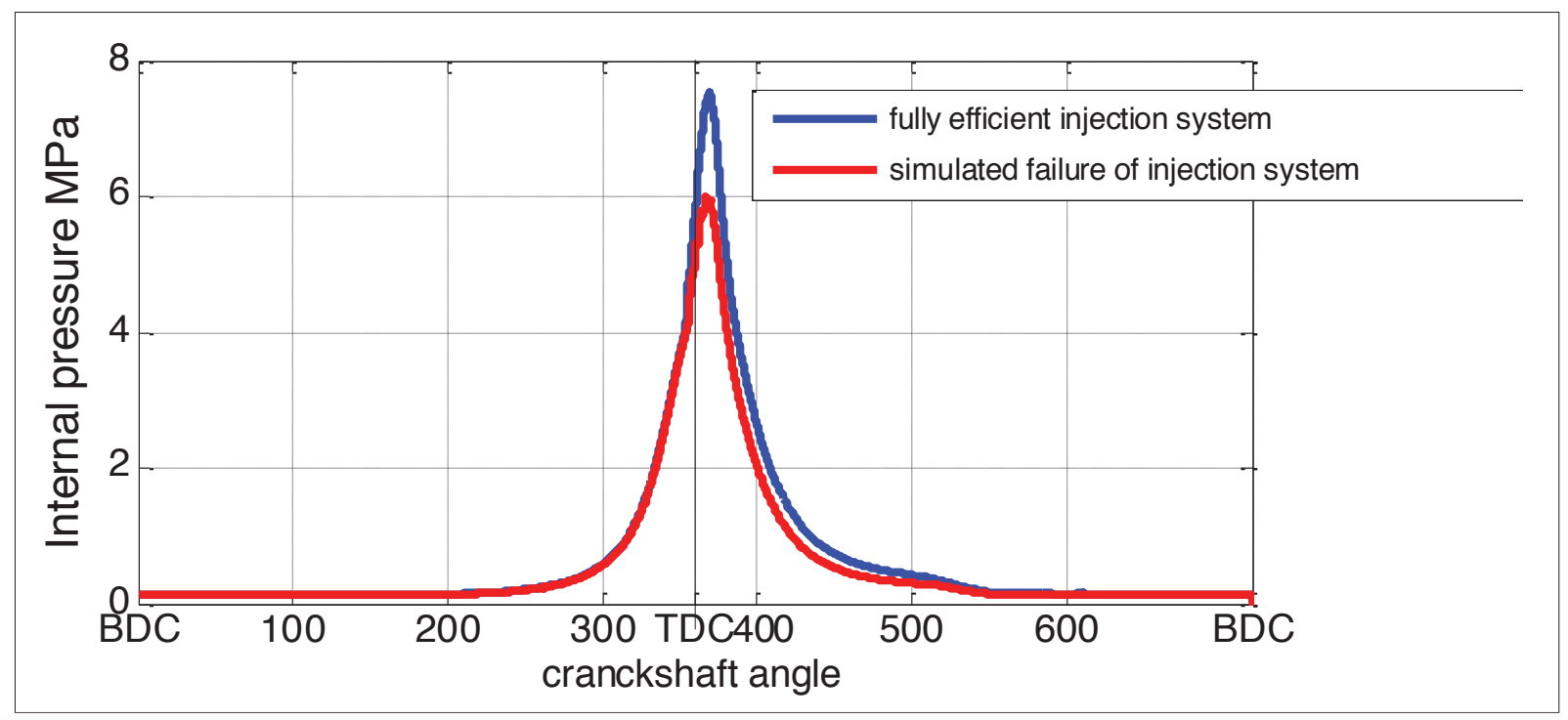

Figure 5.

Result of models of internal cylinder pressure simulation, two cases: properly working injector and malfunctioning one.

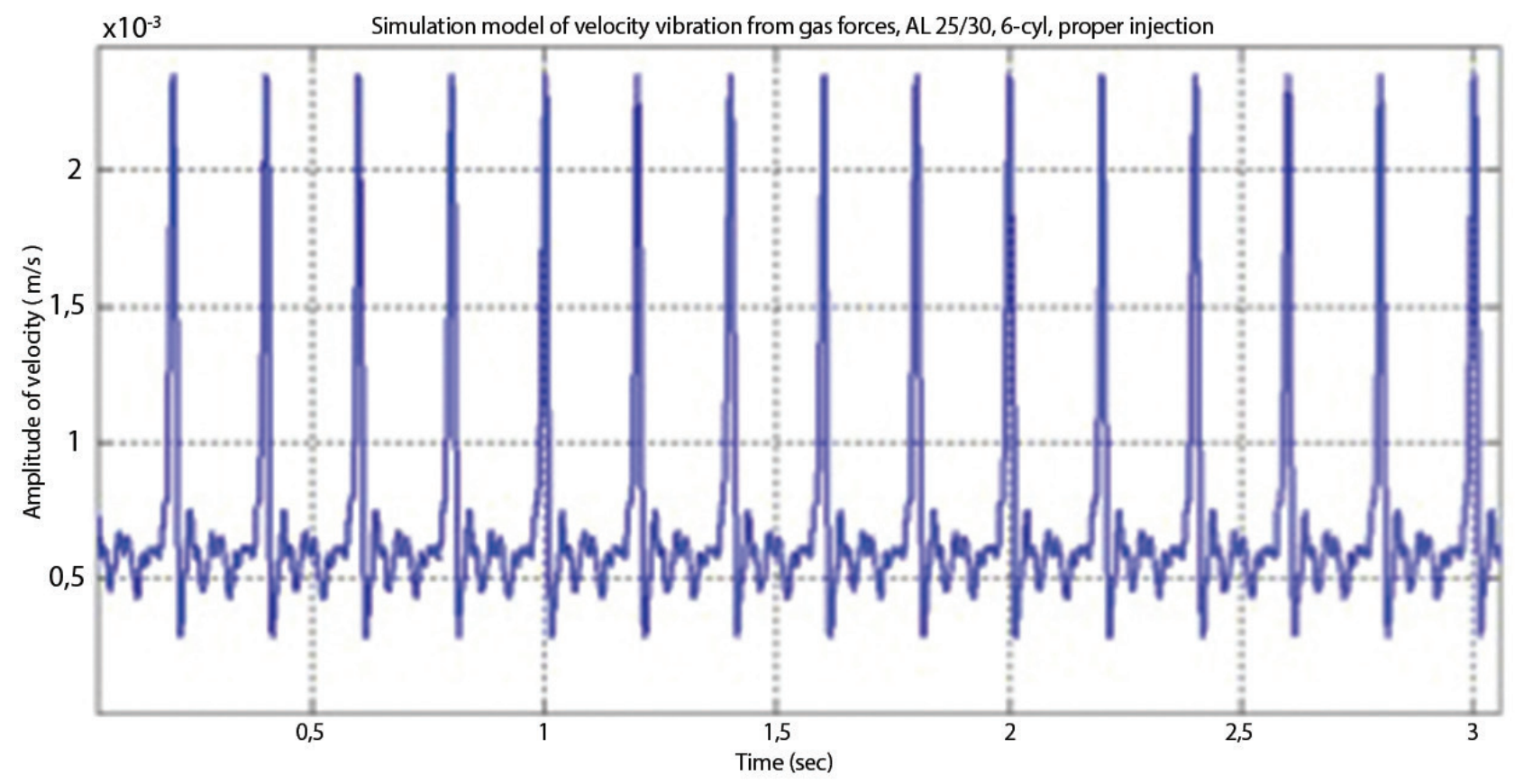

Figure 6.

Result of model of gas pulses excitation as a velocity of vibration, load $20 \%$, efficient working fuel. 


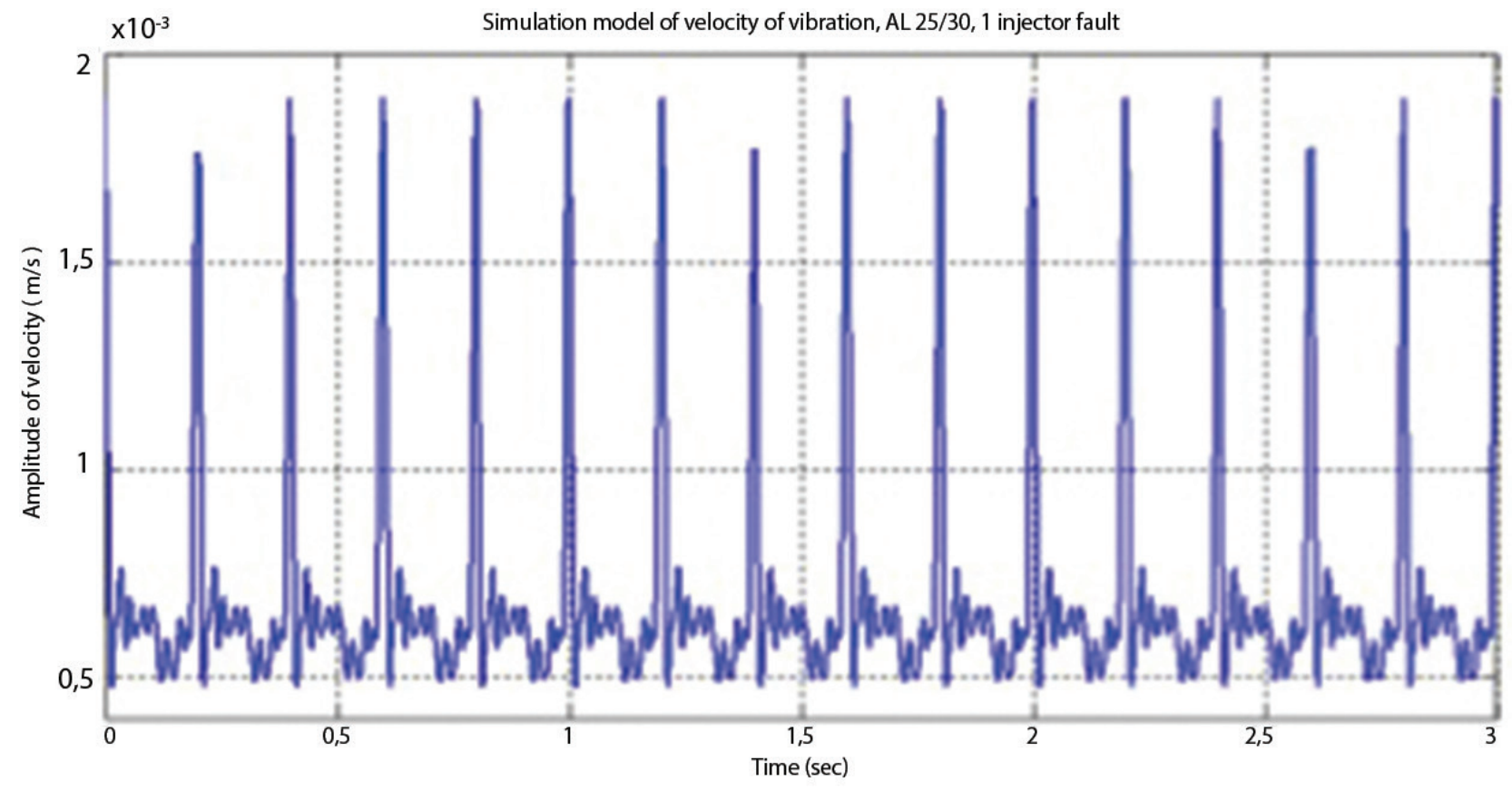

Figure 7.

Result of gas pulses excitation simulation as velocity of vibration, load $20 \%$, malfunction of 1 injector.

The second model of fuel combustion gas forces excitation is based on the harmonically excited step function. The step value of the function was determined by the gas pressure indicator diagram recorded on the $8 \mathrm{AL} 25 / 30$ engine. The forces excited on the engine crankshaft were calculated from the combustion pressure values. The differential equation of excitation has the following form due to the scheme in Figure 2:

$$
m \ddot{x}+c \dot{x}+k x=F \cdot \sigma(t)
$$

or

$$
\ddot{x}+2 n \dot{x}+a^{2} x=\frac{F}{m} \cdot \sigma(t)
$$

with the initial values: $x(0)=\dot{x}(0)=0$.

Transformations of both sides of the equation (25) are as follows:

$$
\left(s^{2}+2 n s+a^{2}\right)=\frac{F}{m} \cdot \frac{1}{s}
$$

thus:

$$
x(s)=\frac{F}{m} \cdot \frac{1}{s\left(s^{2}+2 n s+a^{2}\right)}
$$

To find the function in the time domain, the expression on the right side of equation (27) is split into simple fractions:

$\frac{1}{s\left(s^{2}+2 n s+a^{2}\right)}=\frac{A}{s}+\frac{B s+C}{s^{2}+2 n s+a^{2}}$

thus:

$1=A\left(s^{2}+2 n s+a^{2}\right)+(B s+C) s$ 

follows:

Equation (29) allows the determination of constants as

$A=\frac{1}{a^{2}}, B=-\frac{1}{a^{2}}, C=-\frac{2 n}{a^{2}}$

Thus, the equation can be written as:

$X(s)=x_{S T}\left(\frac{1}{s}-\frac{s+n}{(s+n)^{2}+\gamma^{2}}-\frac{n}{\gamma} \cdot \frac{\gamma}{(s+n)^{2}+\gamma^{2}}\right)$

where:

$x_{S T}=\frac{1}{s} ; \quad \gamma=\sqrt{\left(a^{2}-n^{2}\right)}$
Using Laplace's transform tables, $x$ is written as a function in the time domain as follows:

$x(t)=x_{S T}\left[1-e^{-n t}\left(\cos (\gamma t)+\frac{n}{\gamma} \sin (\gamma t)\right)\right]$

Finally, the function takes the form for each of the cylinders of the 4-stroke engine as follows:

$$
\begin{aligned}
x(t)= & x_{S T}\left[1-e^{-n t}\left(\cos (\gamma t)+\frac{n}{\gamma} \sin (\gamma t)\right)\right] \\
& \sin \left(\pi \omega t+\delta_{i}\right)
\end{aligned}
$$

The results of the simulation of gas forces velocity vibration using step function are shown in Figures 8 - 9.

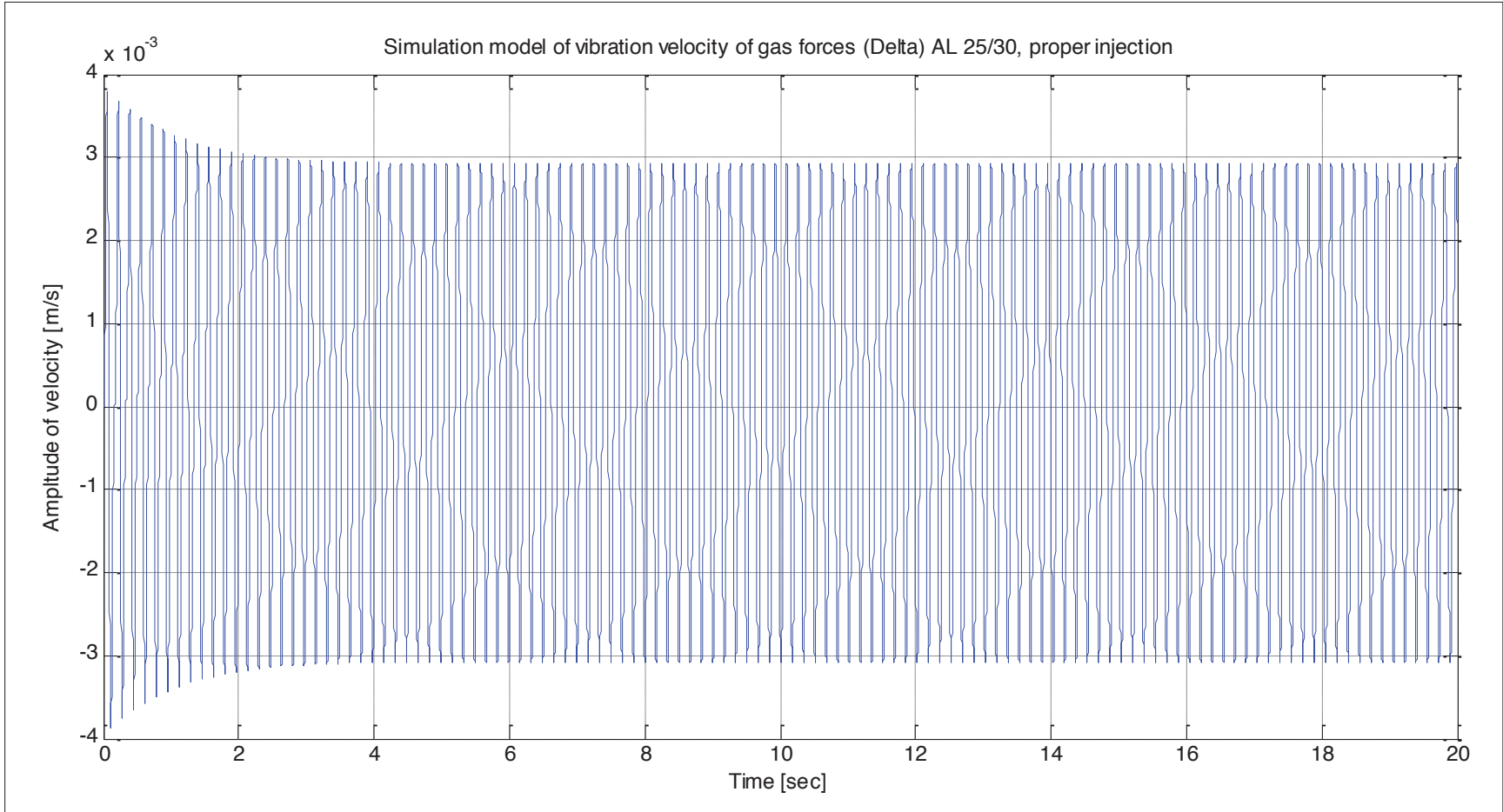

Figure 8.

Result of efficiently working fuel installation simulation, engine $8 \mathrm{AL} 25 / 30,6$-cylinder, load $\mathrm{T}=20 \% \mathrm{~T}_{\max }$. 


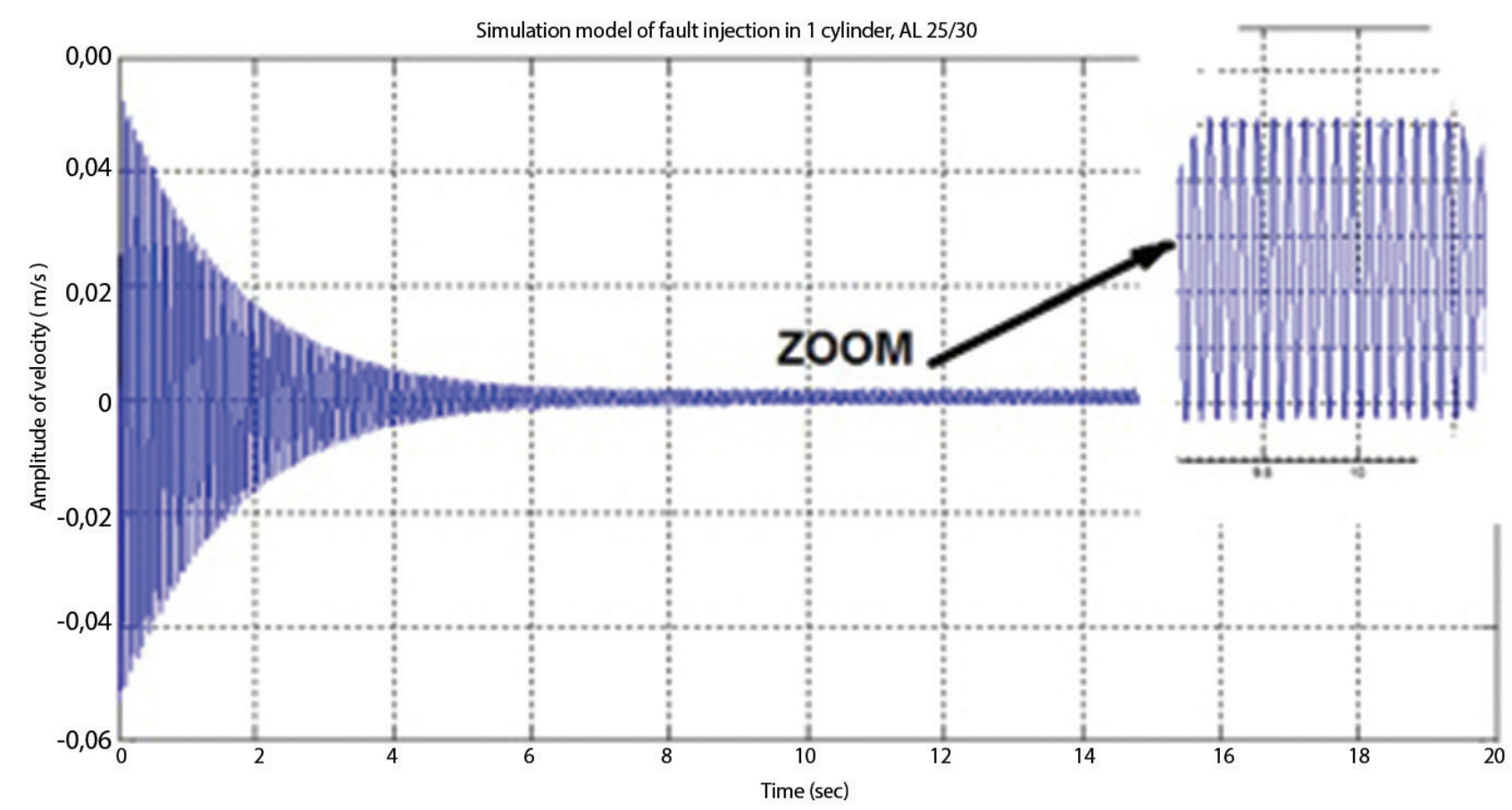

Figure 9.

Result of malfunctioning one injector of the fuel installation simulation, engine 8AL 25/30, 6-cylinder, load $T=20 \% \mathrm{~T}_{\max }$

\section{AUXILIARY MACHINES' EXCITATIONS}

Vibration measurements on the diesel engine head show strong interference with the auxiliary equipment and coupled mechanisms. The basic dynamic forces come from the camshaft mechanism and turbocharger. The other coupled devices such as pumps, fans, etc. have little effect on the dynamics of the engine and are not functionally related to the quality of fuel injection.

The camshaft installation model assumes a poly-harmonic step function whose acceleration is directly proportional to the stiffness of the valve springs and inversely proportional to the mass of the valves. The camshaft speed is $1 / 2$ the crankshaft rotational speed. The vibration velocity model from the installation camshaft operation is shown in Figure 11.

Reduced pressure injection greatly influences the operation of the turbocharger by fluctuating the enthalpy values of the exhaust gas supplied to the turbine (Costall, 2007; Dziubak and Karczewski, 2016). The model of properly working fuel system involves only the residual impact of the rotor unbalance. The injector fault introduces the gas-dynamic unbalance expressed by the mass flow modulation (Korczewski and Zacharewicz,
2009; Podevin et al., 1999). Experimental studies have allowed the development of an empirical formula describing the effect of gasless unbalance in the form:

$$
\begin{aligned}
F= & m_{g a s}\left(\sum_{(i=1)}^{n}\left(\bar{A}_{i}\right) \cdot \sin 0,5 \omega t\right. \\
& +\sum_{(i=1)}^{n}\left(\bar{A}_{i}\right) \cdot \sin \omega t+0,25 \sum_{(i=1)}^{n}\left(\bar{A}_{i}\right) \cdot \sin 2 \omega t \\
& +0,5 \sum_{(i=1)}^{n}\left(\bar{A}_{i}\right) \cdot \sin 3 \omega t \\
& +0,15 \sum_{(i=1)}^{n}\left(\bar{A}_{i}\right) \cdot \sin 4 \omega t \\
& \left.+0,2 \sum_{(i=1)}^{n}\left(\bar{A}_{i}\right) \cdot \sin 5 \omega t\right)
\end{aligned}
$$

where $m_{\text {gas }}-$ mass of gas,

$i$ - number of cylinders,

$A i$ - individual coefficient for engine type,

$\omega$ - rotational speed of the rotor.

The vibration simulation of the turbocharger supplied by modulated gas flow is presented in Figure 11. 


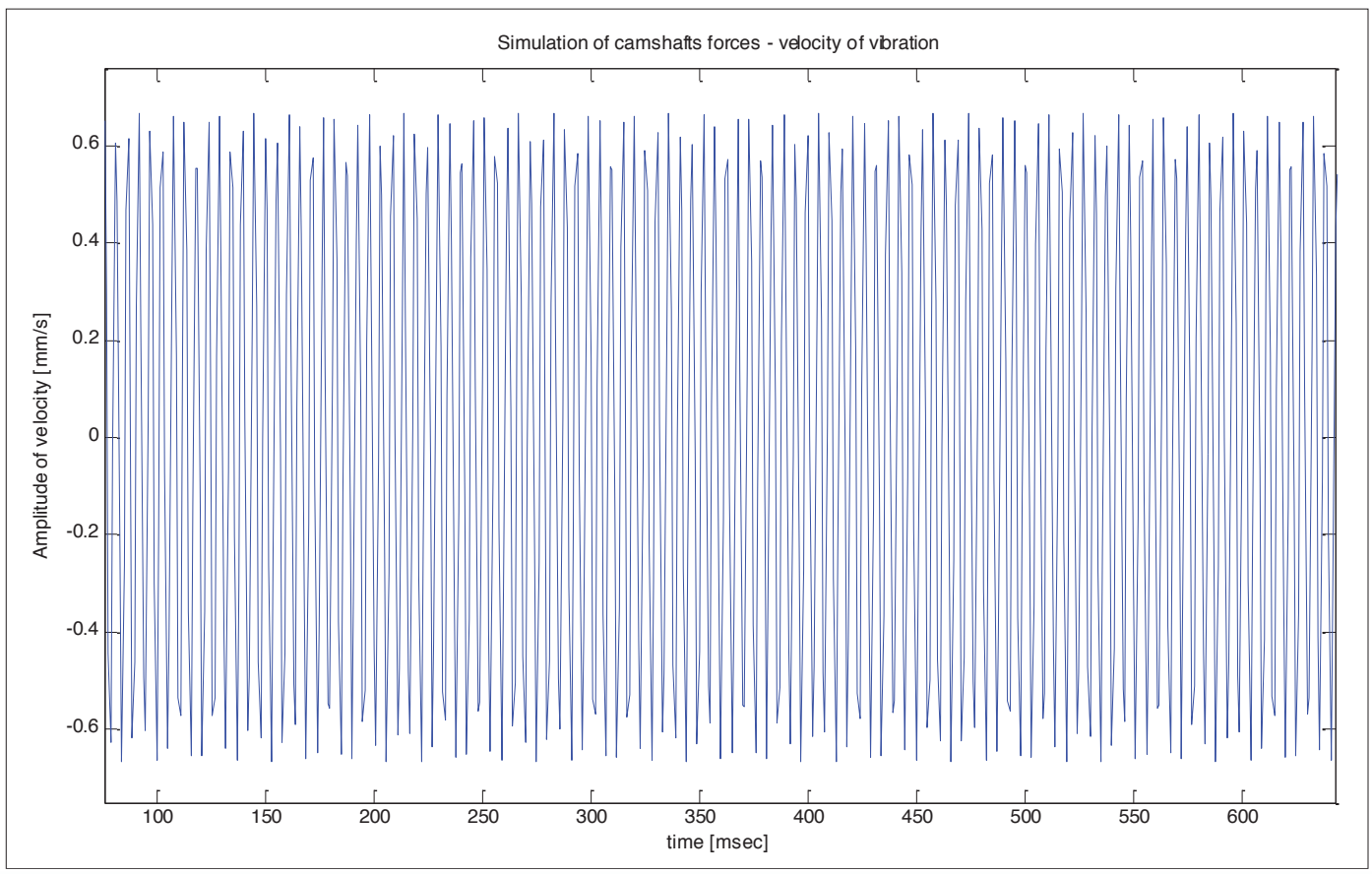

Figure 10.

Result of vibration velocity of camshaft installation simulation, engine type $8 \mathrm{AL} 25 / 30, \mathrm{n}_{\mathrm{DE}}=900 \mathrm{rpm}$, load $\mathrm{T}=20 \% \mathrm{~T}_{\text {max }}$.

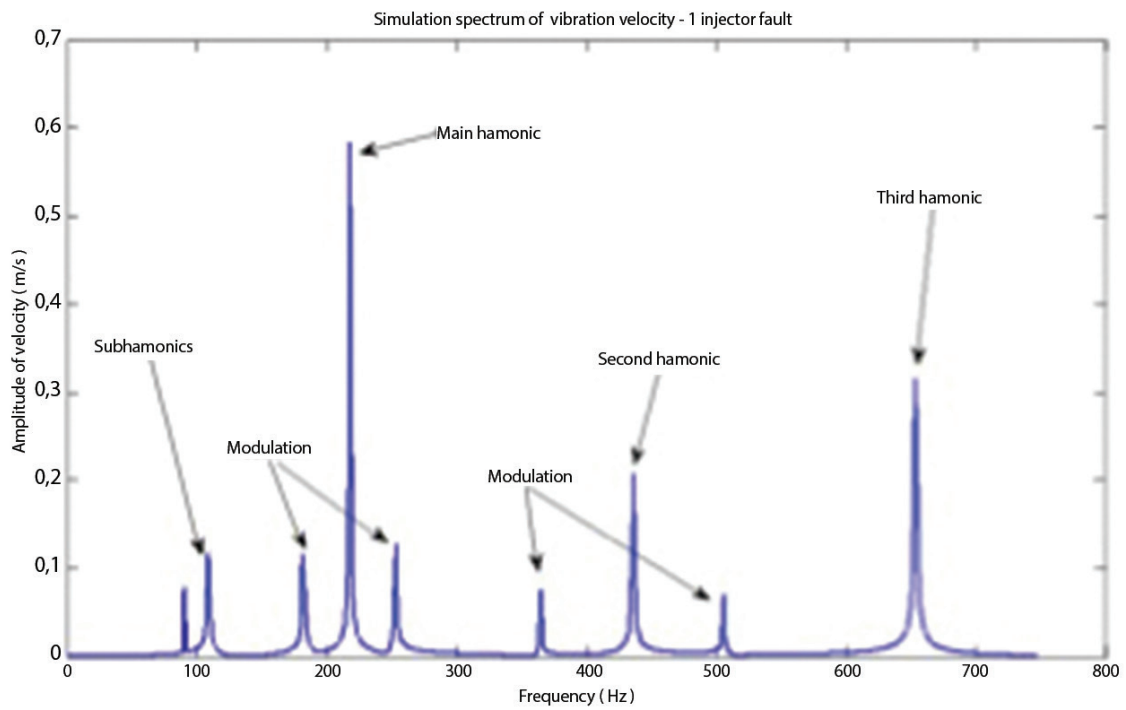

Figure 11.

Result of the spectrum of turbocharger excitation by modulation of gas flow (simulation model).

The main difference between the turbocharger velocity vibration spectrum of efficiently working fuel installation and the faulty working injector are:
- increased values of main harmonics connected to the rotor speed

- $\quad$ appearance of the primary sidebands and subharmonics (Yipeng et al., 2014). 


\section{FULL SCALE DIAGNOSTIC MODEL}

As mentioned above, additive model of interacting forces was adopted. Analyses of the results of simulation of the engines working with efficient and with malfunctioning fuel systems were carried out 5 seconds after the start of the simulation
(Lewińska, 2016; Lus, 2011; Venkateshmohan and Kumar, 2015). For all the analyzed internal forces, it was the time period after which the values of root mean square vibration parameters for the subsequent time periods did not change. Simulation of the time waveform and spectrum for the efficiently working systems is shown in Figures 12 and 13.

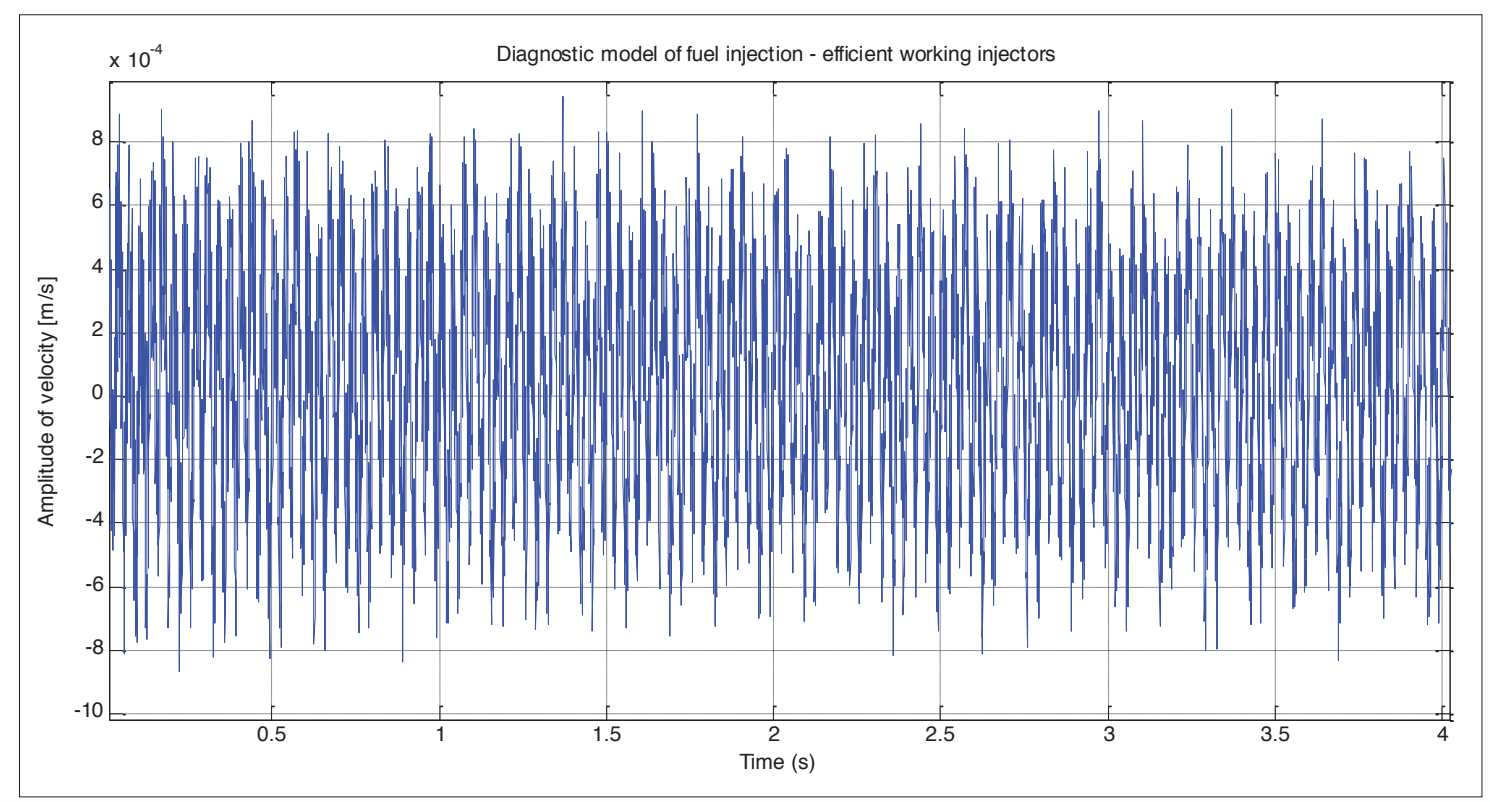

Figure 12

Result of efficiently working fuel injectors simulation - time waveform.

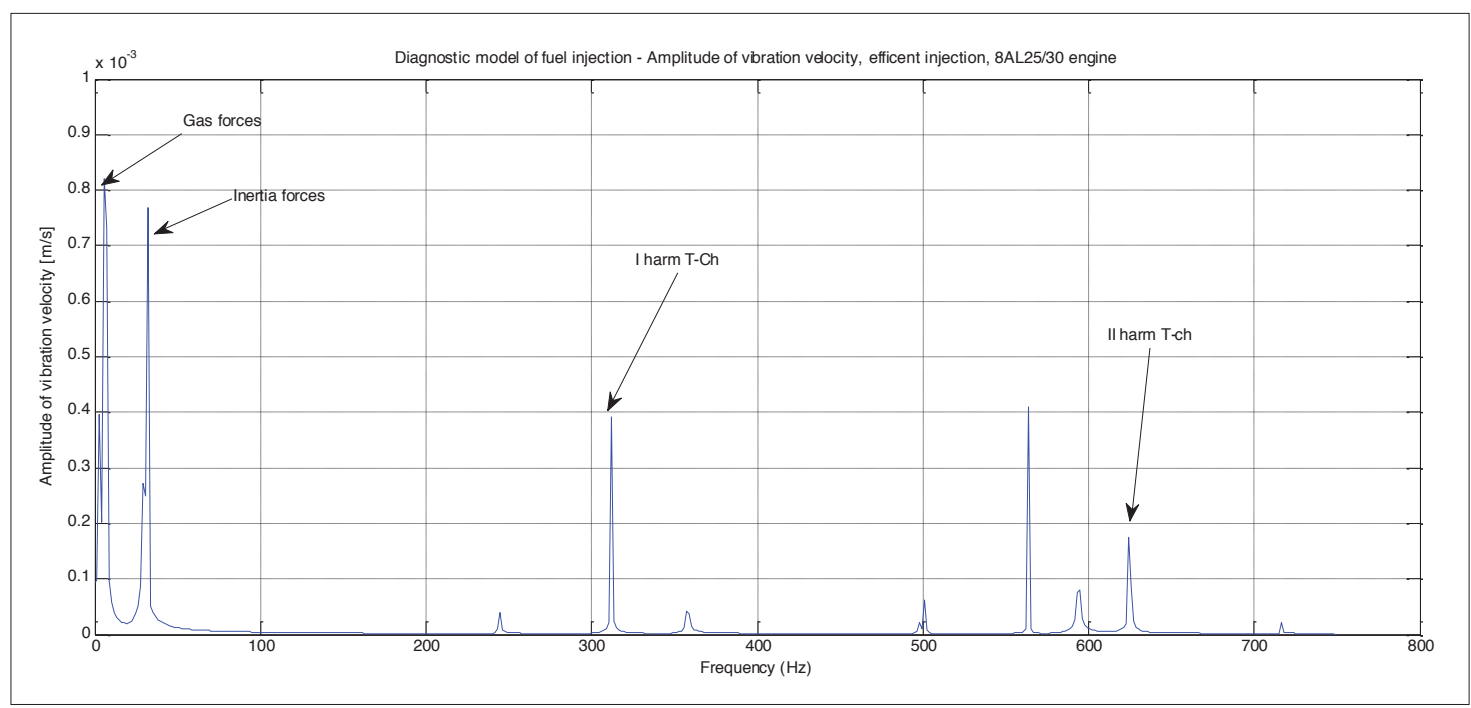

Figure 13.

Result of spectrum of efficiently working fuel injector simulation. 


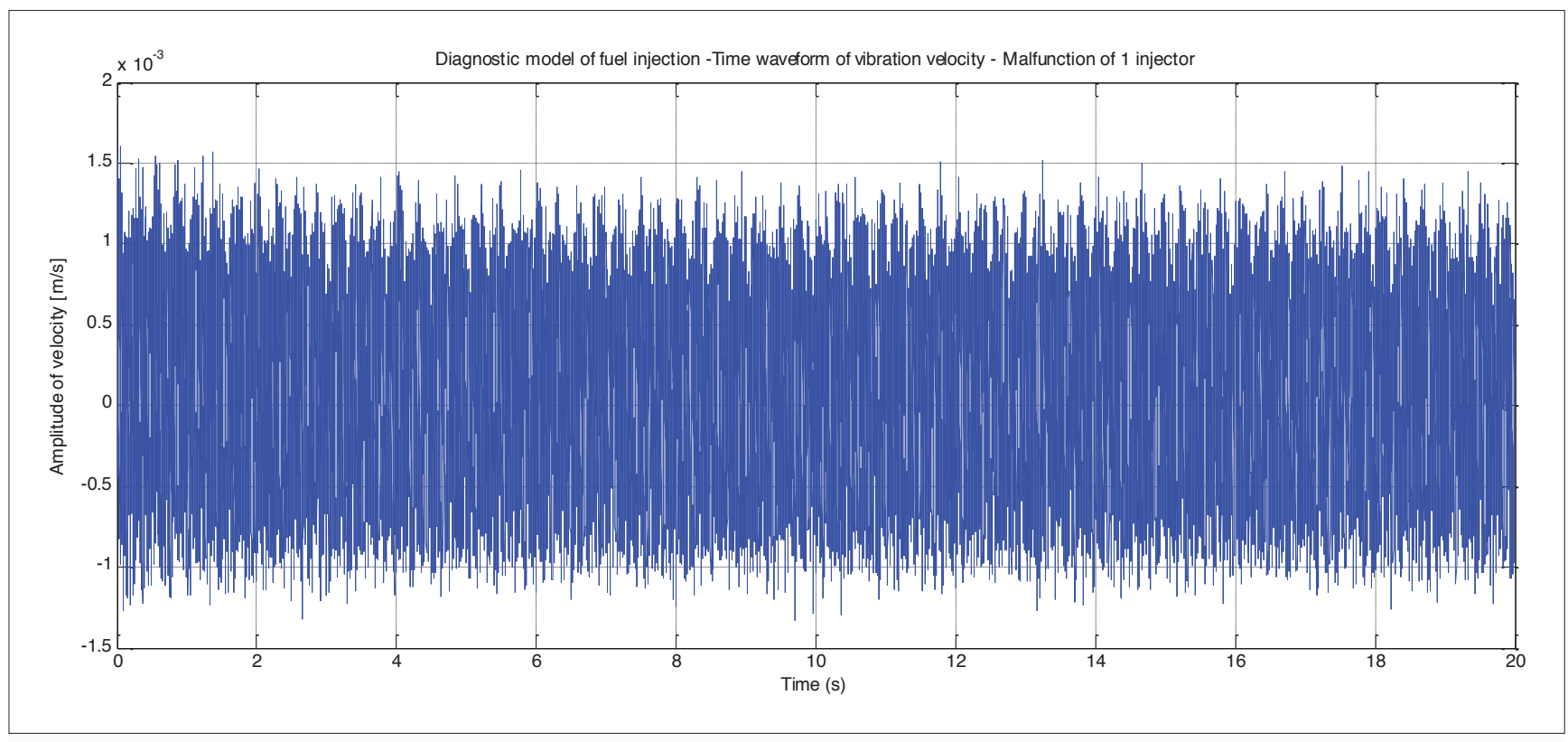

Figure 14.

Result of time waveform model of malfunction of 1 fuel injector (simulation model).

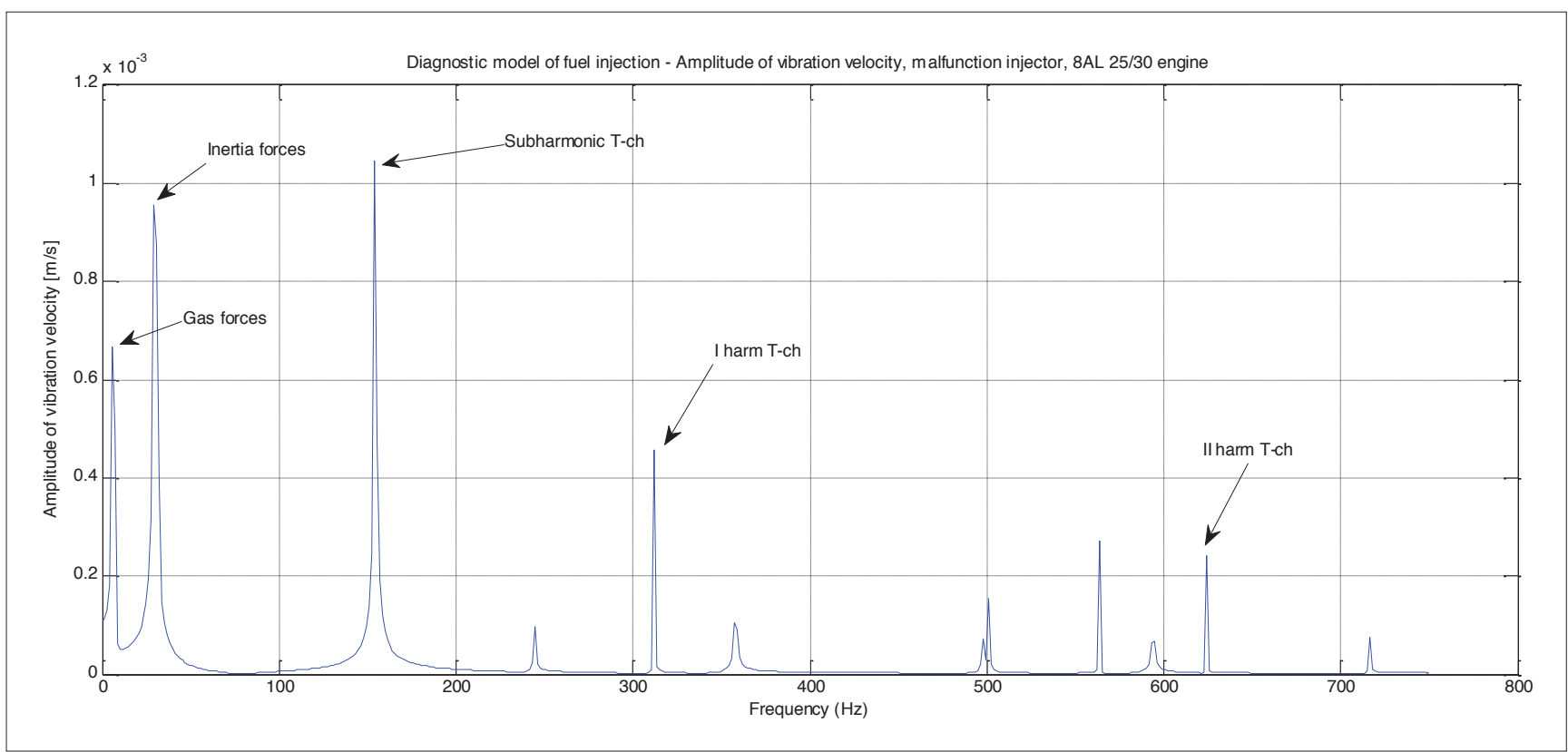

Figure 15.

Result of malfunction of one fuel injector (simulation spectrum). 
Introduction of a full-scale diagnostic model of disturbances, such as lowering the combustion pressure in one cylinder, is shown in Figures 14 and 15.

The effect of the change is the decrease in the vibration amplitude value from the combustion process and the increase in the harmonic amplitudes and their sidebands for the operating turbocharger. As a result of the general symptoms of lowering the injection pressure of one or more injectors will reduce the harmonic value from the combustion process and increase the value of root mean square of vibration velocity.

\section{MODEL IDENTIFICATION}

The identification of the model relies on the analysis of the errors between the parameters of the recorded test on the stand and the model parameters. Due to the lack of simultaneous signals in measurements and in the model, the analysis was done only in the range of frequencies and amplitude values.
Compatibility of the frequencies of the forces in the model and in the engine was not a problem because of understanding the kinematics of the object. Finding the fitting function results in readjustment of the the model, and all the forces fit in the range of the amplitude values for the considered operating states. The function of matching the coefficients of successive amplitudes was calculated as follow:

$C_{f}=-6^{-4} f_{k}^{2}+0,009 f_{k}+0,445$

where: $C_{f}$ - value of amplitude matching coefficient for $k$ frequency, $f_{k}$ - successive frequencies.

During all the tests, one engine speed $\mathrm{n}=750 \mathrm{rpm}$ and 3 loads values i.e. $20 \%, 50 \%, 75 \%$ were analyzed. The obtained values of the fitting function is monotonic. It means that some tests with different engine speeds are possible. Table 1 shows the mean error values with respect to the model-engine relation.

Table 1.

Example of mean relative error analyses for load $20 \% \mathrm{~T}_{\max }$.

\begin{tabular}{|c|c|c|c|c|c|}
\hline & \multicolumn{2}{|c|}{ Value on engine } & \multicolumn{2}{|c|}{ Value on model } & \multirow{2}{*}{$\begin{array}{l}\text { Mean } \\
\text { relative error } \\
{[\%]}\end{array}$} \\
\hline & Proper injector & $\begin{array}{l}\text { Malfunction of } \\
\text { injector }\end{array}$ & Proper injector & $\begin{array}{l}\text { Malfunction of } \\
\text { injector }\end{array}$ & \\
\hline $\begin{array}{l}\text { Gas forces harmonic } \\
\text { V [mm/s] }\end{array}$ & 0.82 & 0.68 & 0.84 & 0.67 & $2.4 / 1.4$ \\
\hline $\begin{array}{l}\text { Inertia forces harmonic } \\
V[\mathrm{~mm} / \mathrm{s}]\end{array}$ & 0.94 & 0.78 & 0.93 & 0.76 & $1.05 / 2.5$ \\
\hline $\begin{array}{l}\text { Turbocharger I harmonic } \\
\text { V }[\mathrm{mm} / \mathrm{s}]\end{array}$ & 0.34 & 0.42 & 0.39 & 0.45 & $14.7 / 7.1$ \\
\hline $\begin{array}{l}\text { Turbocharger II harmonic } \\
\text { V [mm/s] }\end{array}$ & 0.15 & 0.21 & 0.17 & 0.22 & $13 / 4.7$ \\
\hline $\begin{array}{l}\text { Turbocharger III * harmonic } \\
\text { A }[\mathrm{mm} 2 / \mathrm{s}]\end{array}$ & 2.26 & 2.86 & 2.38 & 3.04 & $5.3 / 6.3$ \\
\hline $\begin{array}{l}\text { Turbocharger IV * harmonic } \\
\text { A }[\mathrm{mm} 2 / \mathrm{s}]\end{array}$ & 1.11 & 1.46 & 1.24 & 1.59 & $11.7 / 8.9$ \\
\hline $\begin{array}{l}\text { VRMS }[\mathrm{mm} / \mathrm{s}] \\
{[2 \div 100 \mathrm{~Hz}]}\end{array}$ & 3.5 & 3.9 & 2.9 & 3.3 & $17 / 15$ \\
\hline
\end{tabular}

The mean relative errors of model harmonics of inertia and gas forces for all the analyzed loads are less than $5 \%$. Due to the natural external forces, the mean relative errors of root mean square of vibration velocity from sideband $2-100 \mathrm{~Hz}$ are less than
$20 \%$. Such results confirm the effectively calculated matching function and the correct frequency structure of the model. The results of the vibration sample measured on the heads of engine cylinders are seen of Figure 16-19. 


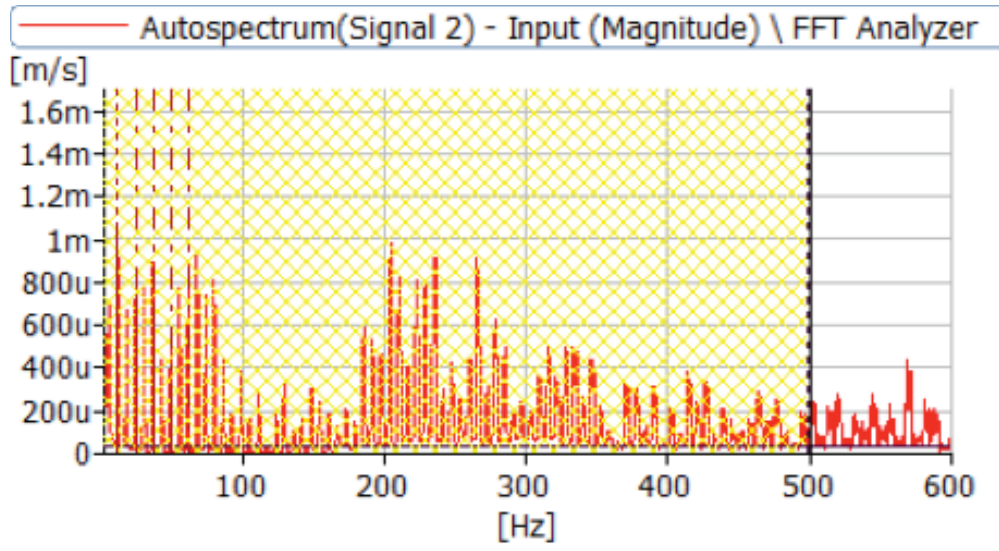

Cursor values

X: $498.50 \mathrm{~Hz}$

Y: $38.0 \mathrm{u} \mathrm{m} / \mathrm{s}$

Delta Cursor

Start: $-0.25 \mathrm{~Hz}$

Stop: $500.25 \mathrm{~Hz}$

Center: $250.00 \mathrm{~Hz}$

Width: $500.50 \mathrm{~Hz}$

Delta: $13.5 \mathrm{~m} \mathrm{~m} / \mathrm{s}$

Total: $13.8 \mathrm{~m} \mathrm{~m} / \mathrm{s}$

Delta/Total: 1.0

Harmonic Cursor

1: $12.5520 \mathrm{~Hz} \quad 1.0556 \mathrm{~m}$ (Funy

Figure 16.

Spectrum of vibration velocity, 8AL25/30 type engine, $n=750 \mathrm{rpm}, \mathrm{T}=20 \% \mathrm{~T}_{\text {max }}$, efficient fuel installation.

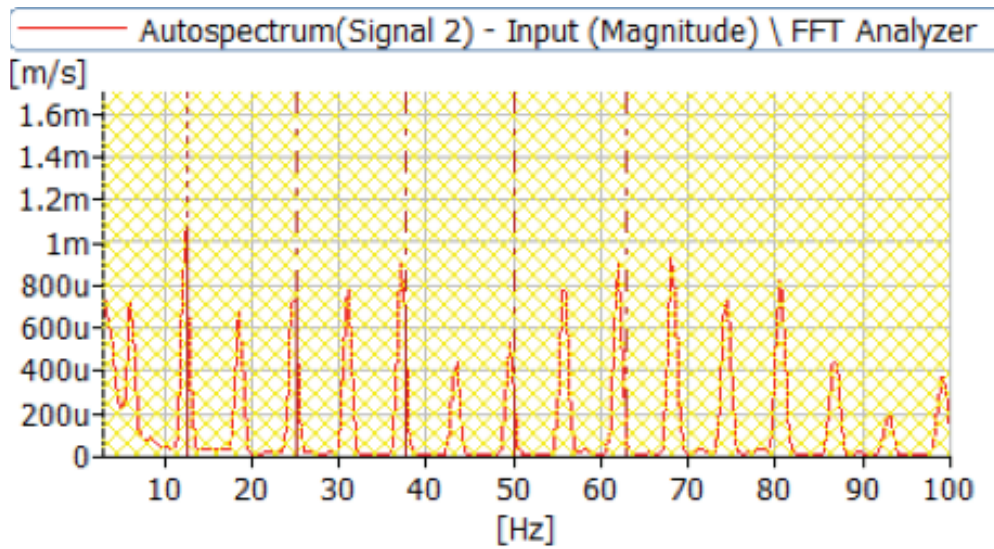

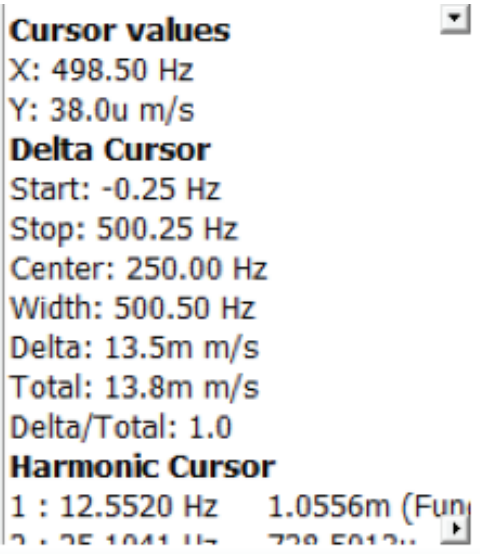

Figure 17.

Spectrum of vibration velocity, $8 \mathrm{AL25} / 30$ type engine, $\mathrm{n}=750 \mathrm{rpm}, \mathrm{T}=20 \% \mathrm{~T}_{\max }$, efficient fuel installation.

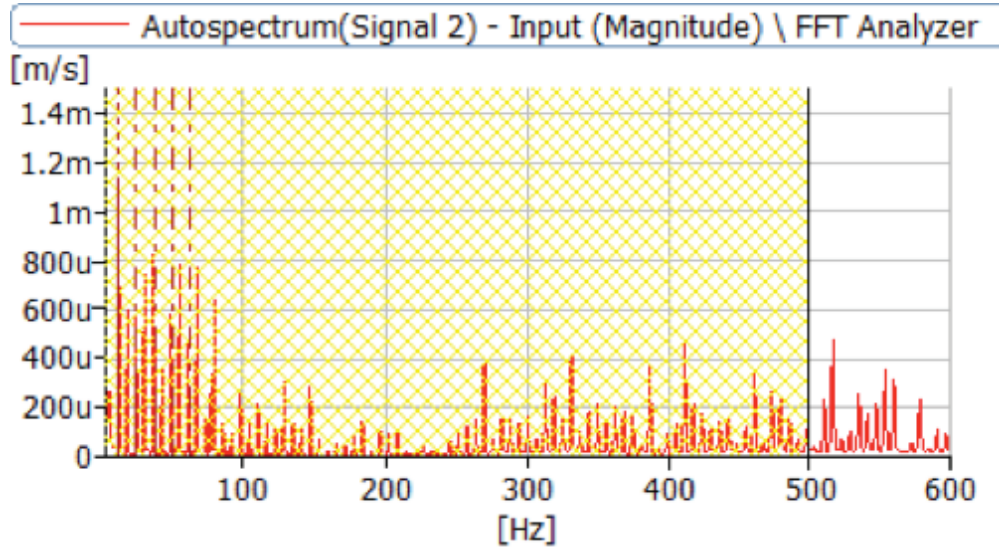

Cursor values

$\mathrm{X}: 1.32 \mathrm{k} \mathrm{Hz}$

Y: $11.3 \mathrm{u} \mathrm{m} / \mathrm{s}$

Delta Cursor

Start: $-0.25 \mathrm{~Hz}$

Stop: $500.25 \mathrm{~Hz}$

Center: $250.00 \mathrm{~Hz}$

Width: $500.50 \mathrm{~Hz}$

Delta: $23.4 \mathrm{~m} \mathrm{~m} / \mathrm{s}$

Total: $23.5 \mathrm{~m} \mathrm{~m} / \mathrm{s}$

Delta/Total: 1.0

Harmonic Cursor

$\begin{array}{ll}\text { 1: } 12.5000 \mathrm{~Hz} & 1.1206 \mathrm{~m} \text { (Fun! } \\ \text { 2. } 25 \mathrm{nnnก} \mathrm{H7} & \mathbf{2 6 1} 11 \text { 20,। }\end{array}$

Figure 18.

Spectrum of vibration velocity, 8AL25/30 type engine, $n=750 \mathrm{rpm}, \mathrm{T}=20 \% \mathrm{~T}_{\text {max }}$, malfunction 1 injector. 


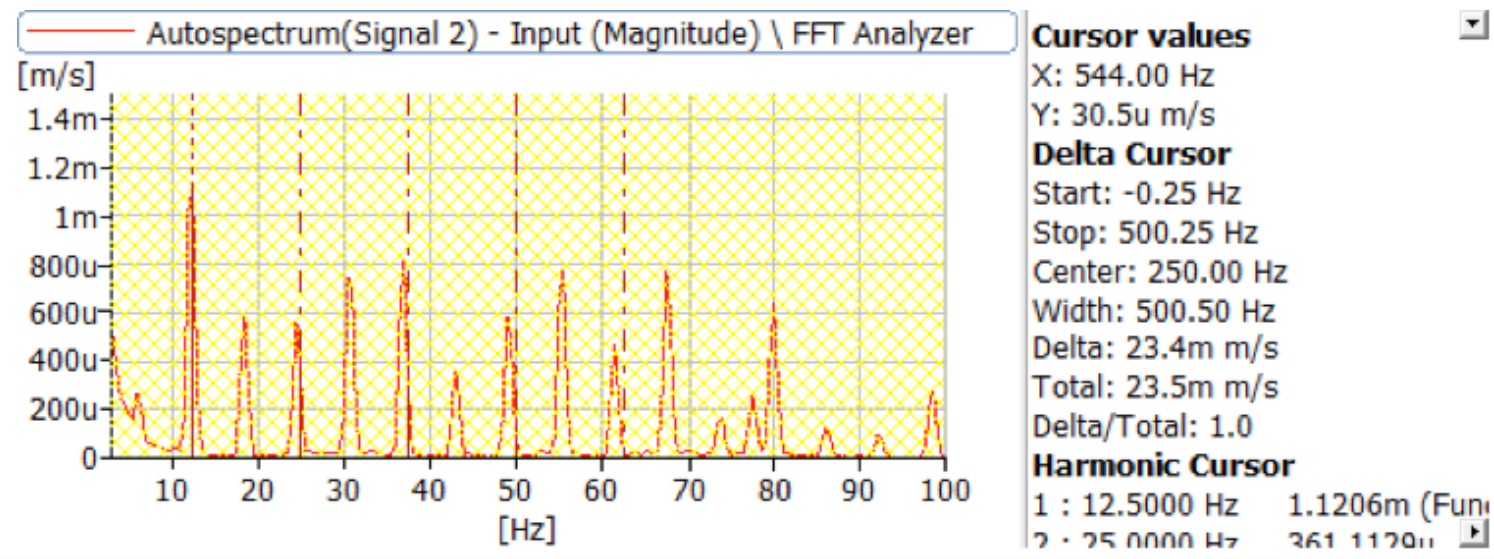

Figure 19.

Spectrum of vibration velocity, 8 AL25/30 type engine, $n=750 \mathrm{rpm}, \mathrm{T}=20 \% \mathrm{~T}_{\max }$, malfunction 1 injector.

Further work on subsequent engine speeds and loads will focus on finding statistical relationships of ratios of amplitude values, which represent vibrational symptoms of a change in the technical condition of an injector. Currently, the number of measurements and simulations is too low for the results to be representative and unambiguous.

\section{CONCLUSIONS}

The main goal of the identified diagnostic diesel engine models is to prepare simulations of typical and uncommon malfunctions for the definition and calculation of diagnostic data. Some symptoms do not need to have specific values because the ratios of symptom values are often equally sensitive. This implies the need for predicting and prioritizing the complexity of the diagnostic model. The high sensitivity model requires resignation of many simplifications; consequently, a huge, multilevel, mathematical model is obtained. The presented model was designed to assess only the technical condition of the fuel installation and, in particular, to reduce the injection pressure on only one injector. The complexity of the response to injection pressure distortion in the model confirms that the overall diagnostic model should be prepared as multi-symptom type model.

The aim of the work was to achieve the identified malfunction of fuel pressure injection model. Further work will be carried out to obtain a full model whose sensitivity will be confirmed for all the rotational speeds of the engine and all operating loads.

\section{REFERENCES}

Armstrong, R. A., (1996), Fault Assessment of a Diesel Engine Using Vibration Measurements and Advanced Signal Processing, MSc thesis, Monterey, California: Theses and Dissertations of Naval Postgraduate School.
Batrak, Y., (2017), Torsional Vibration Calculation Issues with Propulsion Systems, Shaft Designer, c/o Machine Support B.V., available at: http://www.shaftdesigner. com/downloads/PAPER\%2520TORSIONAL\%2520VIBRATION\%2520CALCULATION\% 2520ISSUES\%2520WITH\%2520PROPULSION\%2520SYSTEMS.pdf, [accessed 5 June 2017.].

Carlucci, A. P., Chiara, F. F. and Laforgia, D., (2006), Analysis of the Relation between Injection Parameter Variation and Block Vibration of an Internal Combustion Diesel Engine, Journal of Sound and Vibration, 295(1-2): 141-164., https://doi.org/10.1016/j.jsv.2005.12.054

Costall, A., (2007), A One-dimensional Study of Unsteady Wave Propagation in Turbocharger Turbines, PhD Thesis, London, UK: University of London.

Dziubak, T. and Karczewski, M., (2016), Operational Malfunctions of Turbochargers Reasons and Consequences, Combustion Engines, 164(1), pp. 13-21.

Jianmin, L., Yupeng, S., Xiaoming, Z., Shiyong, X. and Lijun, D., (2011), Fuel Injection System Fault Diagnosis Based on Cylinder Head Vibration Signal, Procedia Engineering, 16, pp. 218 - 223.,

https://doi.org/10.1016/j.proeng.2011.08.1075

Kiijarvi, J., (2003), Diesel Fuel Injection System Simulation, Dissertation, Espoo: Helsinki University of Technology.

Korczewski, Z. and Zacharewicz, M., (2009), The Analysis of a Diagnostic Informativeness of Gas Dynamic Parameters in a Marine Diesel Engine Turbocharging System through an Entropy Function, Combustion Engines, 137(2), pp. 19-25., https://doi.org/10.1515/pomr-2015-0007

Lalić, B., Račić, N. and Radica, G., (2017), Two-Stroke Low Speed Diesel Engine Simulation Model for NOx Analysis, Transactions on Maritime Science, 6(1), pp. 14 $-23$.

https://doi.org/10.7225/toms.v06.n01.002

Lewińska, J., (2016), The influence of fuel injection pump malfunctions of a marine 4-stroke Diesel engine on composition of exhaust gases, Combustion Engines, 167(4), pp. 53 - 57.,

https://doi.org/10.19206/CE-2016-405

Lus, T., (2011), Vibro-acoustic Methods in Marine Diesel Engines Diagnostics, Journal of KONES Powertrain and Transport, 18(3), pp. $203-210$.

Podevin, P., Descombes, G. and Pluviose, M., (1999), Simulation of a Turbocharged Diesel Engine, European Automotive Congress, Barcelona, June 30 - July 2, pp. 1-10. 
Sabau, A., Barhalescu, M. and Oanta, E., (2012), Modeling of High-pressure Fuel Injection Systems, Annals of DAAAM for 2012 \& Proceedings of the 23rd International DAAAM Symposium, 23(1), pp. 1019-1022.

Venkateshmohan, V. and Kumar, M., (2015), Predictive Diesel Combustion Using DI-Pulse in GT-Power, MSc Thesis, Göteborg, Sweden: University of Technology, Department of Applied Mechanics Division of Combustion.
Yipeng, C., Dayuan, Z., Huijun, G. and Xiuzhen, M., (2014), Study on Vibration Control Methods of Diesel Engine Fuel Injection System, The 21st International Congress on Sound and Vibration, Beijing, China, July 13-17, pp. 1-8., available at: https://www. iiav.org/icsv21/content/papers/papers/full_paper_640_20140303133623865.pdf 